\title{
Induced Regenerative Elastic Matrix Repair in LOXL1 Knockout Mouse Cell Cultures: Towards Potential Therapy for Pelvic Organ Prolapse
}

\author{
Venkataraman $\mathrm{L}^{1,3}$, Lenis $\mathrm{AT}^{1}$, Couri BM ${ }^{1}$, Damaser $\mathrm{MS}^{1,2}$ and Ramamurthi $\mathrm{A}^{1 *}$
}

${ }^{1}$ Department of Biomedical Engineering, Cleveland Clinic, Cleveland, OH, USA

${ }^{2}$ Advanced Platform Technology Center, Louis Stokes Cleveland VA Medical Center, Cleveland, OH, USA

${ }^{3}$ Department of Bioengineering, Clemson University, USA

\begin{abstract}
Impaired elastic matrix remodeling occurs in reproductive tissues after vaginal delivery. This has been linked to development of pelvic organ prolapse (POP), for which there currently is no pharmacologic therapy. Hyaluronan oligomers and transforming growth factor beta 1 (termed elastogenic factors, EFs), have been shown to significantly enhance tropoelastin synthesis, elastic fiber assembly and crosslinking by adult vascular smooth muscle cells (SMCs). The goal of this study was to ascertain, if these factors similarly improve the quantity and quality of elastic matrix deposition by vaginal SMCs (VSMCs) isolated from lysyl oxidase like-1 knock out (LOXL1 KO) mouse model of POP. Cells isolated from whole vagina of a LOXL1 KO mouse (multiparous, stage 3 prolapse) were cultured and identified as SMCs by their expression of various SMC markers. Passage 2 vaginal SMCs (VSMCs; $3 \times 10^{4} / 10 \mathrm{~cm}^{2}$ ) were cultured for 21 days with EFs. Cell layers and spent medium aliquots were assessed for elastin content and quality. EF-treated VSMCs proliferated at a similar rate to untreated controls, but synthesized more total elastin, primarily in the form of soluble matrix elastin. Elastin mRNA was also increased compared to controls. The elastic matrix was significantly denser in EF-treated cultures, which was composed of more mature, non-interrupted elastic fibers that were absent in controls. The results are promising towards development of a therapy to enhance regenerative elastic matrix repair in post-partum female pelvic floor tissues.
\end{abstract}

Keywords: Elastin; Smooth muscle cell; Vagina; Pelvic floor disorders; Prolapse; Growth factors; Elastogenic

\section{Introduction}

Chronic enzymatic disruption of, and intrinsic reduction in cellular capacity to repair and/or regenerate highly cross-linked elastic matrix, occurs with aging and contributes significantly to the development and exacerbation of several pathological disorders, characterized by loss of extracellular matrix (ECM) structure [1-4]. One such condition, pelvic organ prolapse (POP), characterized by abnormal herniation of the pelvic organs, correlates with vaginal delivery of children and becomes increasingly more common post-menopause, and with age $[5,6]$. The lifetime risk of surgery for POP is as high as $11 \%[7,8]$, with a reoperation rate for POP or related conditions, between $6-12 \%[8-10]$. An excess of 1 billion USD is spent annually in surgical treatment of POP [11]. Drug-based therapeutic strategies to reduce the need for reoperation and regress, or prevent the progression of POP are critical to improve the quality of life for patients, and reduce associated costs of long-term treatment; however, no such therapies currently exist.

Clinically, POP and other manifestations of female pelvic floor disorders (FPFD) appear to be associated with heritable genetic alterations in actin, myosin and extracellular matrix (ECM) proteins $[12,13]$. Expansion and softening of pelvic tissues in preparation for parturition and resorptive involution post-partum occurs via degradation of elastic fibers [14,15]. Defects in homeostasis of the pelvic connective tissues could thus exacerbate tissue damage due to impaired post-partum matrix repair. There is increasing evidence that elastin abnormalities and FPFD may be associated, since POP patients with complete procidentia and women with more than two vaginal deliveries, exhibit reduced elastin content in their uterosacral ligaments [3], which could be due to the reduced elastin mRNA expression and matrix synthesis observed in these patients [16-18]. Neutrophil elastase activity is also increased and $\alpha-1$ antitrypsin (an inhibitor of neutrophil elastase) expression decreased in vaginal tissues of FPFD patients, suggestive of increased elastic matrix breakdown [19]. Further, genes involved in elastin metabolism and degradation (e.g., elafin) are differentially expressed in the vagina in women with stress urinary incontinence (SUI), suggesting that impaired elastin remodeling is important in the pathophysiology of SUI, as well as POP [20]. Recent insight into the molecular pathogenesis of POP implicates abnormal connective tissue (CT) homeostasis and repair, with aberrations of enzymes responsible for cross-linking tropoelastin, the monomeric form of elastin, into matrix structures [11]. Such aberrations could lead to the high rate of unsuccessful outcomes with surgical repair, which relies on preserved native tissue structure. Disruption of the CT matrix can potentially lead to increased complications, such as mesh extrusion and protrusion, which is the likely basis for recent warnings, as to use of such meshes by the Food and Drug Administration in the United States [21]. Restoration of disrupted ECM composition, content, and structure in POP tissues may, therefore, prove critical to slow, arrest, or even regress POP development.

In light of evidence that aberrant or frustrated elastic matrix repair occurs in POP tissues, inducing regeneration of elastic matrix may be useful as a therapy to deter the condition. In recent studies, hyaluronan oligomers (HA-o) have been shown to significantly enhance elastin precursor molecule (tropoelastin) synthesis, elastic fiber assembly, and cross-linking by vascular smooth muscle cells [22,23]. Transforming

*Corresponding author: Ramamurthi A, Department of Biomedical Engineering Cleveland Clinic, Cleveland, OH, USA, Fax: 216-444-9198; E-mail: ramamua@ccf.org

Received August 20, 2012; Accepted September 25, 2012; Published September 28, 2012

Citation: Venkataraman L, Lenis AT, Couri BM, Damaser MS, Ramamurthi A (2012) Induced Regenerative Elastic Matrix Repair in LOXL1 Knockout Mouse Cell Cultures: Towards Potential Therapy for Pelvic Organ Prolapse. J Tissue Sci Eng 3:120. doi:10.4172/2157-7552.1000120

Copyright: (C) 2012 Venkataraman L, et al. This is an open-access article distributed under the terms of the Creative Commons Attribution License, which permits unrestricted use, distribution, and reproduction in any medium, provided the original author and source are credited. 
growth factor beta-1 (TGF- $\beta 1$ ) is also known to enhance elastin production, by suppressing matrix metalloproteinases (MMPs) and elastases [24], and increasing tissue inhibitor of metalloproteinases (TIMPs) [25] and lysyl oxidase (LOX) protein levels [26]. HA-o and TGF- $\beta 1$, together termed elastogenic factors (EFs), synergistically enhance tropoelastin and matrix elastin synthesis, crosslinking, and fiber formation. This has been demonstrated by EF-treatment, in both healthy [27] and diseased (e.g., aneurysmal) [28,29] adult vascular smooth muscle cell (SMC) culture, known to be inherently poor in regenerating elastic matrix.

To explore future potential for an elastic matrix regenerationbased therapy to treat POP, the present study sought to determine the effects of EFs on vaginal smooth muscle cells (VSMCs) harvested from a lysyl oxidase like-1 (LOXL1)-deficient mouse, a well characterized animal model that simulates clinical POP. VSMCs enable elastic matrix synthesis and cross linking via secretion of precursor molecules and enzymes, such as LOXL1, that are critical to catalyze the formation of mature fibers. This work has the potential to augment current treatments for POP, and complement upcoming therapeutics to improve success rates and reduce the need for re-operation.

\section{Materials and Methods}

\section{Isolation and culture of mouse vaginal smooth muscle cells}

Whole vagina was harvested just below the cervix to the introitus, from a prolapsed LOXL1 knockout mouse (parity=3; prolapse grade $=3$ ), according to animal protocols approved by IACUC. The tissue sample was minced into pieces (2-3 mm long) and incubated in Dubelco's Modified Eagle Medium (DMEM)-F12 containing 20\% v/v fetal bovine serum (PAA Scientific, Ontario, Canada), 1\% v/v Penstrep (Thermo Scientific, Rockford, IL), and $175 \mathrm{U} / \mathrm{ml}$ collagenase II (Worthington Biochemicals, Lakewood, NJ), for 20 minutes at $37^{\circ} \mathrm{C}$. This was followed by a second digestion in the above solution, supplemented with 0.25 $\mathrm{mg} / \mathrm{ml}$ of elastase III (Worthington Biochemicals, Lakewood, NJ) for 45 minutes. Cells were finally pelleted at $1000 \mathrm{rpm}$, reconstituted and cultured in DMEM-F12 containing $20 \% \mathrm{v} / \mathrm{v}$ serum and $1 \% \mathrm{v} / \mathrm{v}$ Penstrep. Subsequent passages were cultured in $10 \% \mathrm{v} / \mathrm{v}$ serum and cells at passage 2-3 were used for the study.

To confirm that the isolated cells were VSMCs, they were immunolabeled for the SMC phenotypic markers caldesmon, a-SM actin, and tropomyosin (Abcam, Cambridge, MA). For cell culture studies, confluent VSMCs were trypsinized and seeded in 6-well plates $(A=10$ $\mathrm{cm}^{2} /$ well), at a density of $3 \times 10^{4}$ cells/ well and cultured for 21 days in $10 \% \mathrm{v} / \mathrm{v}$ serum- rich media. Cell cultures supplemented with EFs at a concentration of $10 \mathrm{ng} / \mathrm{ml}$ of TGF- $\beta 1$ (Peprotech Inc., Rocky Hill, $\mathrm{NJ}$ ) and $2 \mu \mathrm{g} / \mathrm{ml} \mathrm{HA}-\mathrm{o}$, served as the 'Treatment' group, while those cultured without EFs represented the 'Control' group.

The EF dose combination tested was one that has been shown in a series of earlier studies, to elastogenically stimulate both rat and human aortal SMCs, both healthy and diseased (i.e., from abdominal aortic aneurysms) $[27,28]$. HA-o mixtures used in this study primarily consisted of 4 -mers ( 75\%), with 6 -mers and 8 -mers, comprising the remaining fraction. They were prepared by digesting high molecular weight HA $\left(1.5 \times 10^{6} \mathrm{Da}\right.$, Genzyme Biosurgery, Cambridge, MA) with testicular hyaluronidase $\left(40 \mathrm{U} / \mathrm{mg}\right.$ at $37^{\circ} \mathrm{C}$ for 18 hours; Worthington Biochemicals, Lakewood, NJ), as previously described [23]. Cell layers were harvested after 21 days of culture for biochemical analysis $(n=6$ cultures/group). Spent medium from each well was pooled with aliquots, previously removed from the same wells, and frozen at $-20^{\circ} \mathrm{C}$ until biochemically quantified for tropoelastin content at the end of the culture period. For imaging the ECM, additional 2-chamber slides were seeded at $10^{4}$ cells/well $\left(\mathrm{A}=2 \mathrm{~cm}^{2}\right)$ and cultured likewise, with or without the EFs.

\section{DNA assay for cell quantification}

The DNA contents within the respective groups of cell cultures were compared to determine the impact of EFs on VSMC growth For analysis, cell layers were harvested after 21 days of culture in $4 \mathrm{ml}$ aliquots of Pi buffer ( $50 \mathrm{mM} \mathrm{Na} \mathrm{HPO}_{4}, 2 \mathrm{mM}$ EDTA, $0.02 \% \mathrm{NaN}_{3}$ ), and then sonicated over ice. Their respective DNA contents were quantified using a Hoerchst dye (Gibco-Invitrogen, Carsbad, CA) -based flourometric assay, as described by Labarca and Paigen [30]. Briefly, sonicated aliquots were incubated with the dye, and dye-bound DNA content was estimated from fluorescence values obtained from excitation at emission peaks at $346 \mathrm{~nm}$ and $460 \mathrm{~nm}$, respectively, using a UV-spectrophotometer (SpectraMax M2, Molecular Devices, Inc., Sunnyvale, CA). Cell counts were then calculated assuming 6 pg of DNA/cell [30].

\section{Hydroxy proline assay for collagen content}

A hydroxyl proline (OH-Pro) assay was used to estimate the collagen content within the EF-treated and control cell layers, as described previously [22]. Briefly, cell layer aliquots harvested in $\mathrm{Pi}$ buffer were hydrolyzed in $6 \mathrm{~N} \mathrm{HCl}$ for 16 hours at $110^{\circ} \mathrm{C}$, dried and reconstituted in Milli- $\mathrm{Q}$ water. $50 \mu \mathrm{l}$ aliquots were assayed in duplicates, to measure the $\mathrm{OH}-$ Pro content in cell layers. Matrix collagen amounts were then calculated on the basis of the $13.2 \% \mathrm{w} / \mathrm{w}$ OH-Pro content of collagen, and normalized to cell numbers of corresponding cell layers.

\section{Fastin assay for elastin content}

A Fastin assay (Accurate Scientific and Chemical Corporation, Westbury, NY) was used to quantify the total amount of elastin deposited within cell layers (matrix elastin), and that released into the culture medium as a soluble precursor (tropoelastin). For each treatment group, tropoelastin in the spent medium was collected and pooled over the culture period, and frozen $\left(-20^{\circ} \mathrm{C}\right)$. To isolate matrix elastin following 21 days of culture, the cell layers were harvested in Pi buffer, digested with equal volumes of $0.1 \mathrm{~N} \mathrm{NaOH}\left(98^{\circ} \mathrm{C}, 1\right.$ hour $)$ and centrifuged to yield a less crosslinked, alkali-soluble supernatant fraction (soluble elastin), and a mature, highly crosslinked, insoluble pellet (insoluble elastin). Since the Fastin assay quantifies only soluble a-elastin, the insoluble elastin was first converted to a soluble form, prior to quantification, by solubilizing it with $0.25 \mathrm{M}$ oxalic acid $\left(95^{\circ} \mathrm{C}, 1 \mathrm{~h}\right.$ our$)$, then filter-centrifuging it (3000 RPM, $\left.10 \mathrm{~min}\right)$ in micro centrifuge tubes fitted with low molecular weight $(10 \mathrm{kDa})$ cutoff membranes (Millipore, Bedford, MA). All three elastin fractions (tropoelastin, and soluble and insoluble matrix elastin) were quantified using the Fastin assay kit.

\section{RT-PCR for mRNA expression of matrix proteins}

Total RNA was isolated from cell layers at day 21 of culture using an RNeasy kit (Qiagen, Valencia, CA), and reverse transcribed into cDNA using iScript cDNA Synthesis kit (Biorad, Hercules, CA), according to the manufacturers' instructions. Gene expression for collagen, elastin, LOX, and fibrillin were evaluated using $1 \mu \mathrm{l}$ of cDNA with Power SYBR $^{\circ}$ Green Master Mix (Applied Biosystems, Foster, CA) $(n=6 /$ case), in the ABI 7500 Real Time PCR System (Applied Biosystems). Specific primers used for collagen-1 (Col1a1), Elastin (Eln), LOX (LOX), and fibrillin-1 (FBN1) [31] were purchased as optimized primer sets from 
Citation: Venkataraman L, Lenis AT, Couri BM, Damaser MS, Ramamurthi A (2012) Induced Regenerative Elastic Matrix Repair in LOXL1 Knockout Mouse Cell Cultures: Towards Potential Therapy for Pelvic Organ Prolapse. J Tissue Sci Eng 3:120. doi:10.4172/2157-7552.1000120

Page 3 of 8

Real Time Primers (Elkins Park, PA). A comparative threshold method [32] was used to quantify the mRNA expression of these genes and was reported as $2^{-\Delta \Delta \mathrm{Ct}}$, with $18 \mathrm{~s}$ serving as the internal control.

\section{Transmission Electron Microscopy (TEM) for visualization of elastic matrix}

Cells cultured in chamber slides were harvested at 21 days of culture, and fixed in $2.5 \% \mathrm{v} / \mathrm{v}$ gluteraldehyde and $4 \% \mathrm{v} / \mathrm{v}$ paraformaldehyde in $2 \% \mathrm{w} / \mathrm{v}$ sodium cacodylate buffer for 12 hours. Samples were then post-fixed in $1 \% \mathrm{w} / \mathrm{v}$ osmium tetroxide and $1 \%$ uranyl acetate ( 1 hour), and dehydrated in a graded ethanol series (50-100\% v/v). Fixed cell layers were embedded in Epon 812 resin and placed on copper grids embedded in pure Eponate for sectioning. Sections ( $85 \mathrm{~nm}$ thickness) were cut using a diamond knife, and stained with uranyl acetate and lead citrate. Sections were imaged using a Philips CM12 electron microscope, operated at $60 \mathrm{kV}$.

\section{Statistical analysis}

All quantitative results were analyzed from $n=6$ independent biological replicate cultures, measurements made in triplicate unless otherwise indicated, and reported as mean \pm standard deviation. Statistical significance between groups was determined by SPSS software, using a simple t-test assuming unequal variance. Results were deemed significant for $p$ values $\leq 0.05$.

\section{Results}

\section{Confirmation of SMC phenotype}

The cells isolated from the LOXL1 KO mouse vaginal tissue labeled positive for the SMC phenotypic markers caldesmon, $\alpha-S M$ actin, and tropomyosin, confirming their identity as VSMCs (Figure 1).

\section{Cell density and ECM synthesis}

There was no statistically significant difference in cell numbers after 21 days of culture between control $\left[(1.6 \pm 0.2) \times 10^{6} /\right.$ well $]$ and treatment $\left[(1.7 \pm 0.2) \times 10^{6} /\right.$ well $]$ groups $(\mathrm{p}=0.289$; Figure 2$)$. Total matrix collagen deposition was also not statistically different between control (346.5 \pm $51.4 \mu \mathrm{g})$ and treatment $(257 \pm 78.4 \mu \mathrm{g})$ cultures $(\mathrm{p}=0.126)$ (Figure 3$)$. On a per cell basis, this trend was maintained $(216.6 \pm 51.4 \mathrm{pg} / \mathrm{cell}$ in control vs $151.9 \pm 42.4 \mathrm{pg} /$ cell in treated groups, $\mathrm{p}=0.092$ ).

Elastin protein content was quantified in terms of tropoelastin, and alkali-soluble and-insoluble matrix elastin components. Tropoelastin synthesis, though noticeably higher in the treatment group (364.78 \pm $54.1 \mathrm{mg} /$ well vs $250.38 \pm 56.1 \mathrm{mg} /$ well in control) was not significantly different $(\mathrm{p}=0.09$; Figure $4 \mathrm{~A})$. Treatment with EFs significantly increased total elastin matrix production $(\mathrm{p}=0.004)$, primarily in the form of alkali-soluble matrix $(6.8 \pm 2.1)$ fold compared to control, $\mathrm{p}=0.04$; Figure $4 \mathrm{~B})$. No significant differences were observed in alkaliinsoluble matrix elastin content.

\section{Expression for matrix protein genes}

Elastin mRNA expression in EF-treated cultures were significantly higher $(3.6 \pm 0.66$ fold, $\mathrm{p}=0.001)$, compared to untreated control cultures (Figure 5). Although, expression of collagen and LOX genes in the EF-treated cultures appeared to be higher than in control cultures, the differences were deemed statistically, not significant $(\mathrm{p}=0.132$ and 0.13 vs. control respectively, for collagen and LOX). Likewise, fibrillin
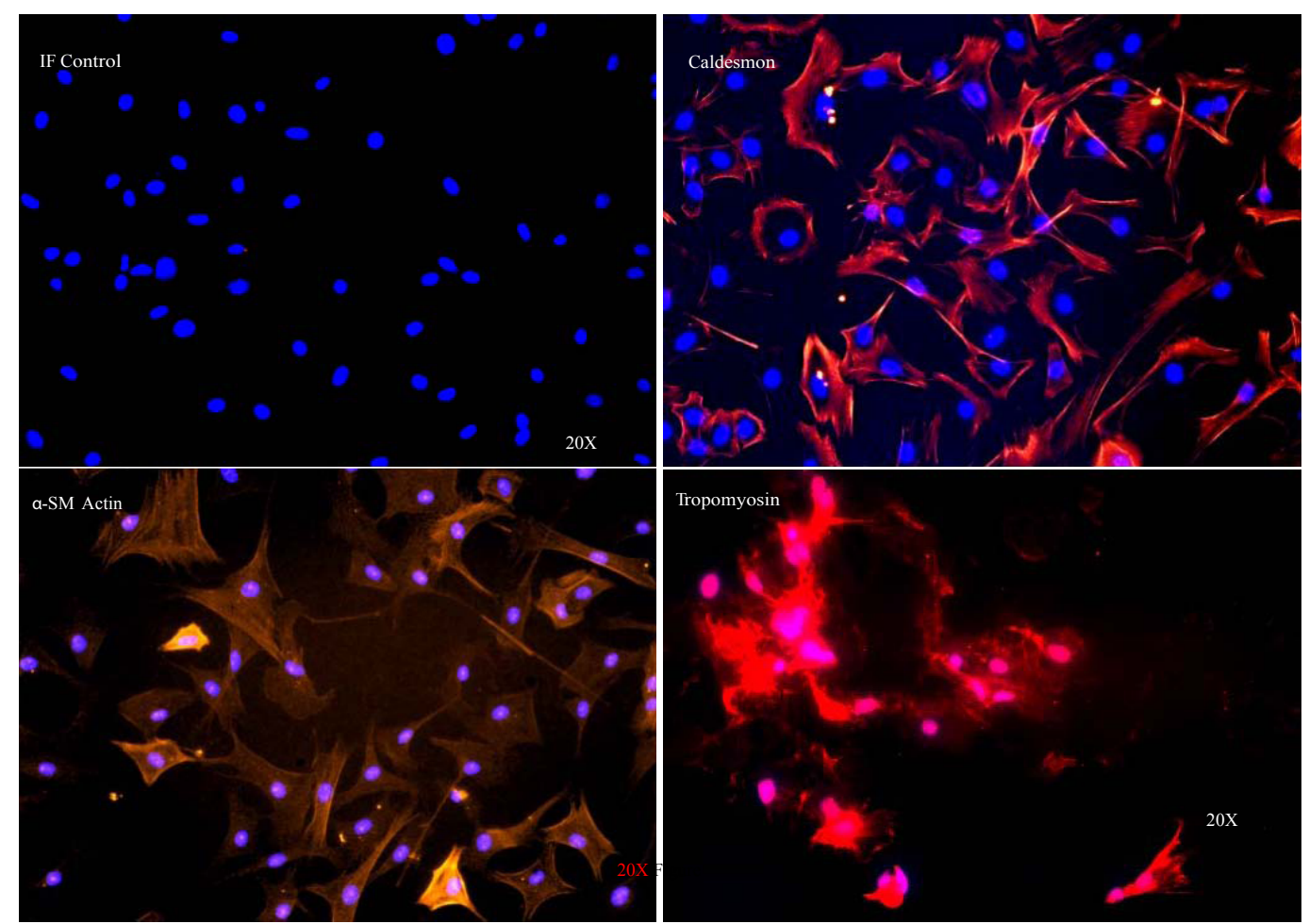

Figure 1: Phenotypic confirmation of primary vaginal cells. Cells isolated by enzymatic digestion of vaginal biopsies were proliferated in DMEM/12 containing $20 \%$ v/v FBS. Cells positively labeled for various SMC markers, such as caldesmon (Alexa Fluor 594, red), a-SM actin (Alexa Fluor 555, orange), and tropomyosin (Alexa Fluor 594, red) confirming the SMC phenotype. Nuclei were labeled with DAPI (blue). 


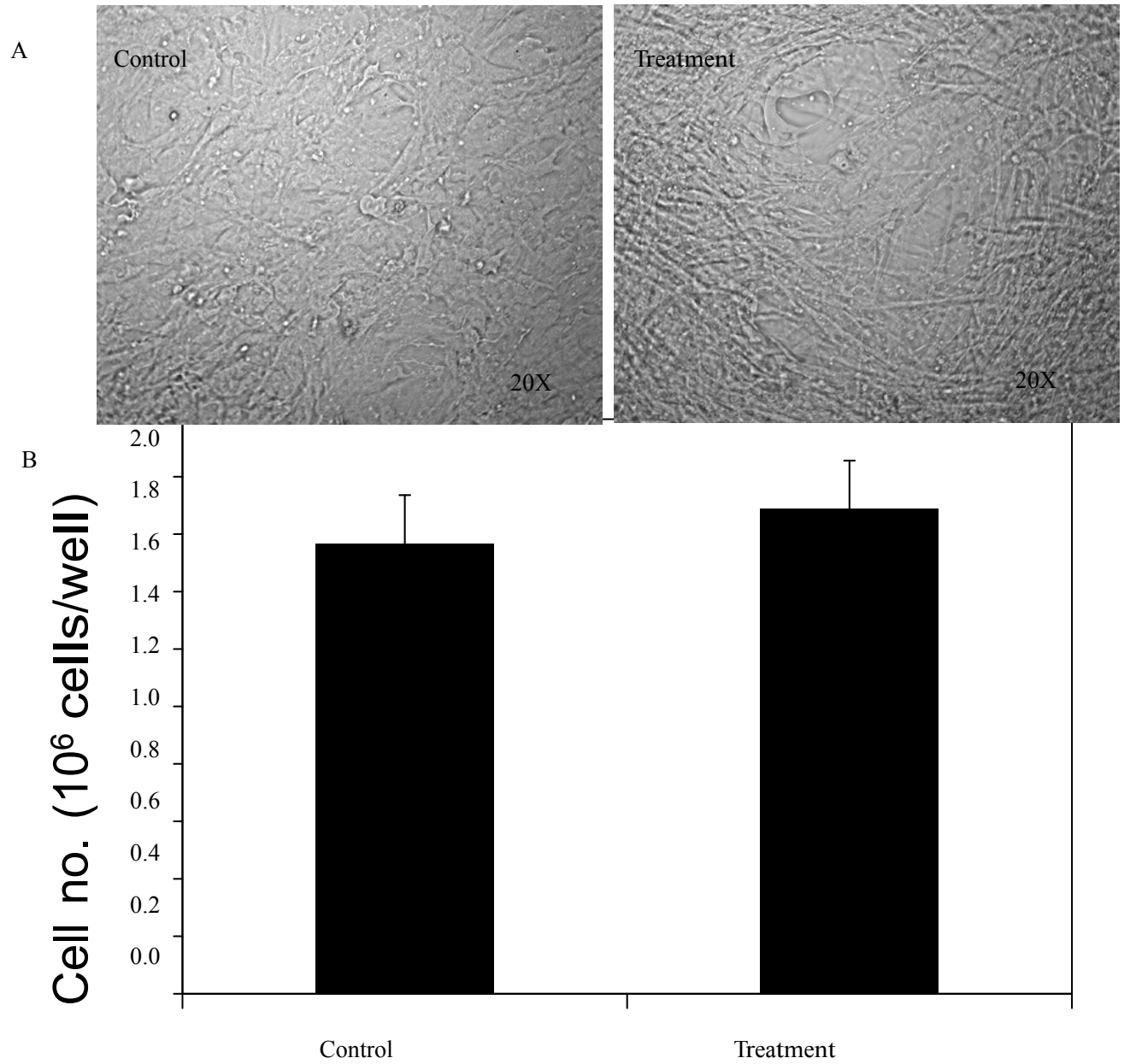

Figure 2: Morphology and cell count of cultured VSMCs. (A) Cell layers at day 21. (B) Cell count at day 21 as determined by a fluorometric assay, showing no significant differences between control and treatment groups.

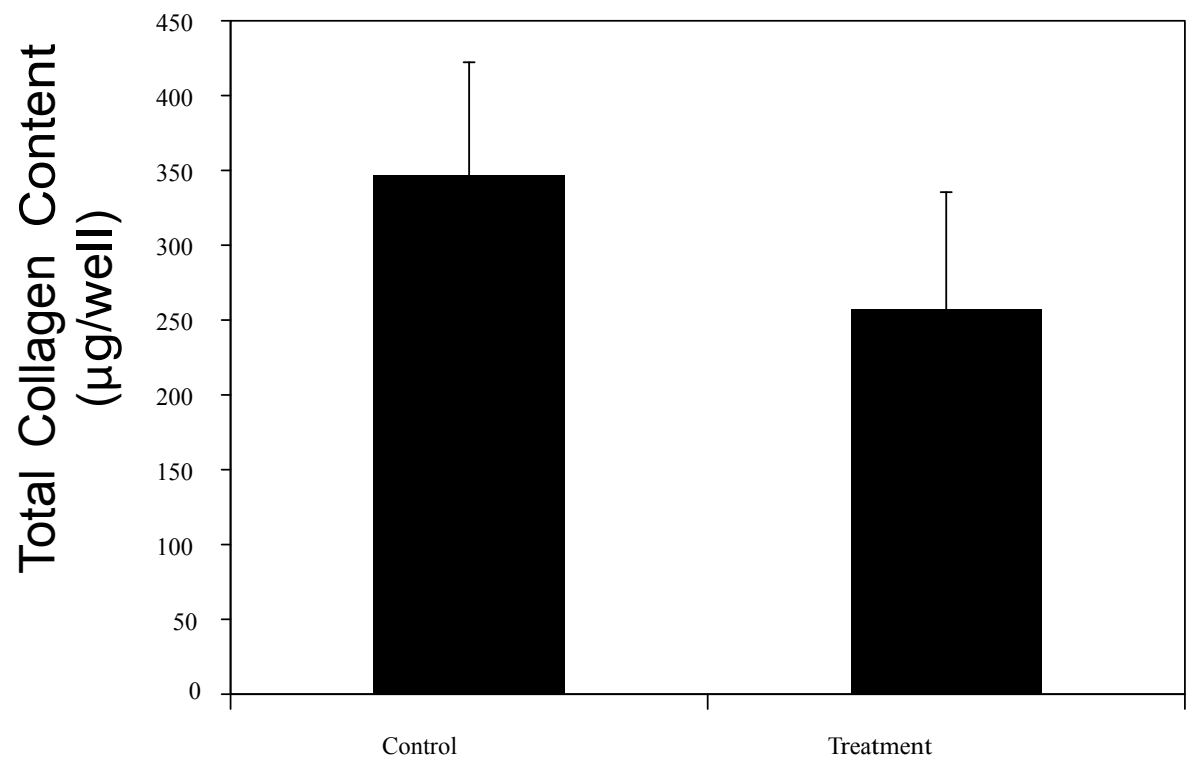

Figure 3: Collagen content quantified in cultures by hydroxyproline assay. No significant difference was observed between the groups. 

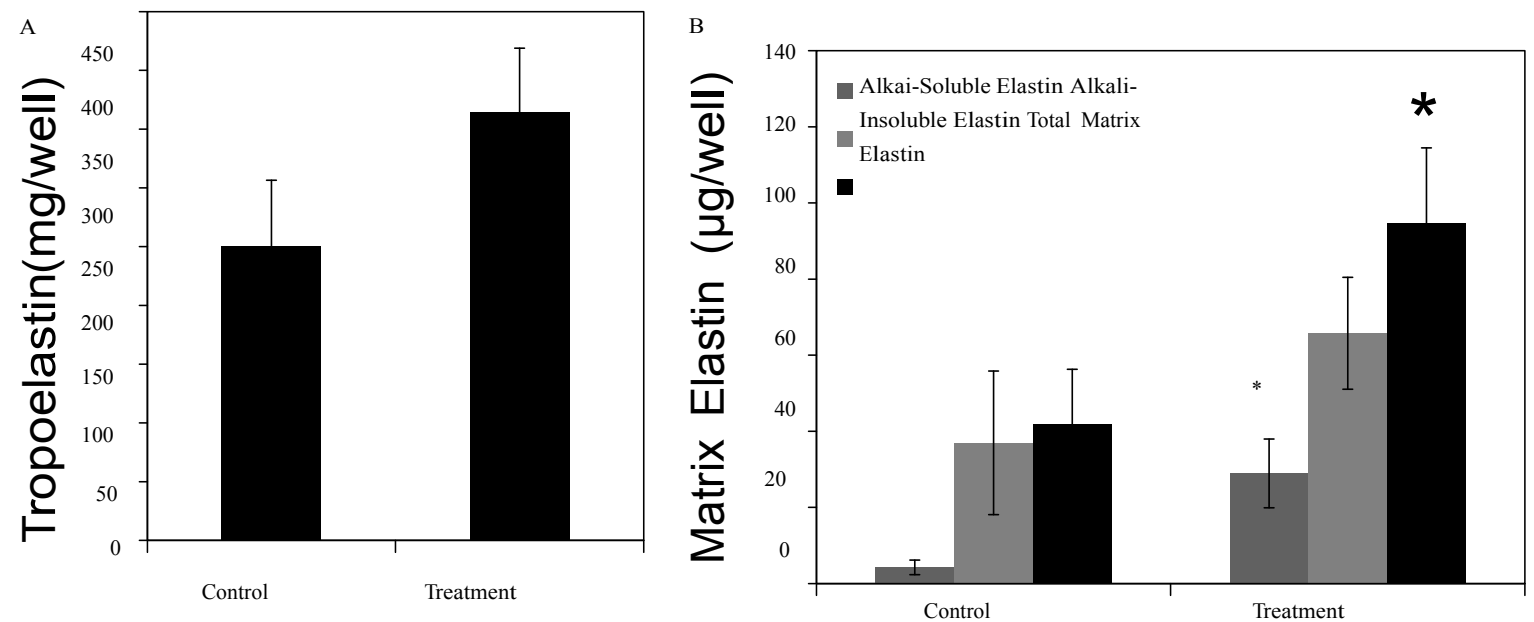

Figure 4: Effects of EFs on elastic matrix synthesis by VSMCs after 21 days of culture. (A) Tropoelastin measured from spent media aliquots. (B) Matrix elastin quantified from cell layers represented in terms of alkali-soluble elastin, alkali-insoluble elastin, and total matrix elastin (soluble+insoluble). Addition of EFs resulted in a $2.6 \pm 1.4(p=0.004)$ fold increase in total matrix elastin, primarily in the form of soluble matrix elastin $(p=0.04)$. '*' represents significant difference from comparable control for $(p<0.05)$.

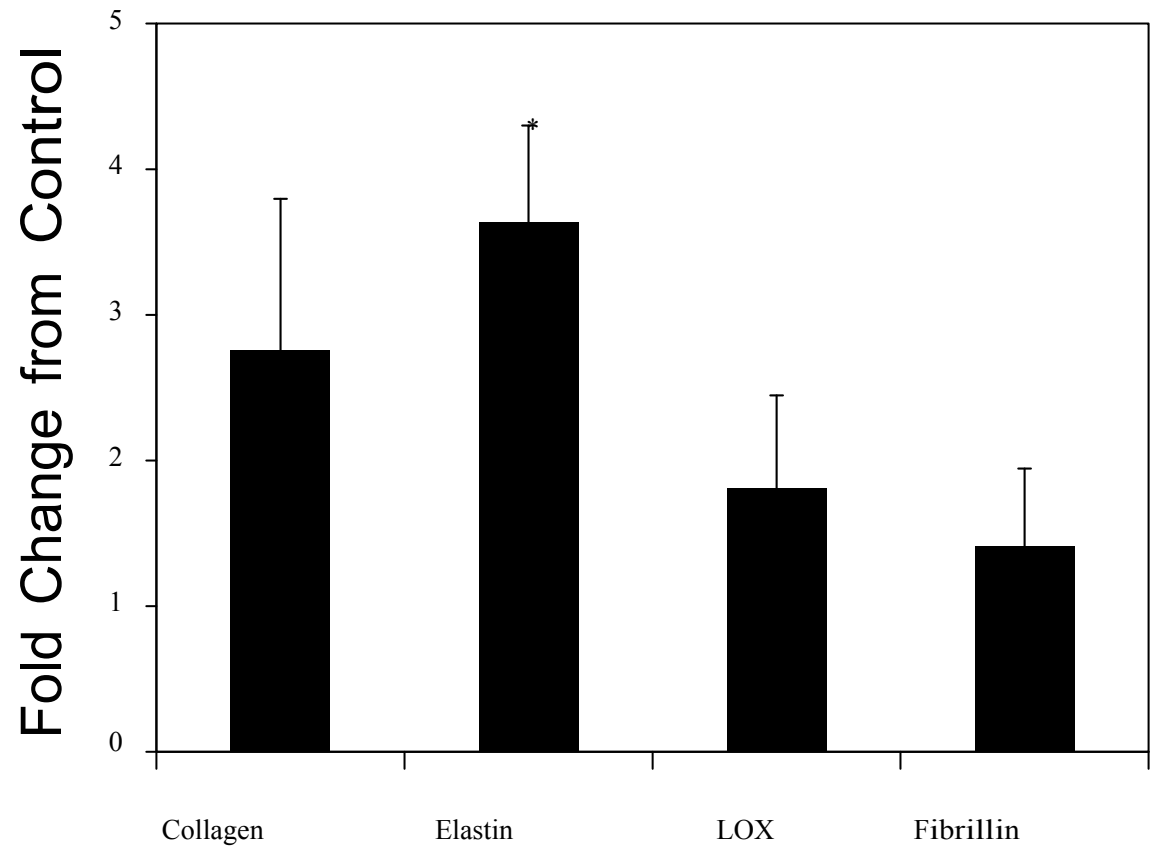

Figure 5: mRNA expressions of collagen, elastin, LOX and fibrillin expressed as fold change from control. ‘*' represents significant difference from control for ( $p<0.05$ ).

mRNA expression levels were not significantly different between treated and control groups ( $\mathrm{p}=0.11$ vs. controls).

\section{Visualization of elastic matrix}

TEM revealed sporadic and aberrant elastin fibers in the control cultures, in contrast to the more mature fibers found in abundance in the EF-treated cultures (Figure 6). Elastic fibers were observed in the form of electron-dense regions, surrounded by dark fibrillin microfibrils in the extracellular space, indicating that the cells were in the process of laying down the fibers.

\section{Discussion}

Connective tissues of the female reproductive tract provide critical structural support to the pelvic organs [33]. Their role in maintaining structural integrity of the pelvic organs can be most appreciated postpartum, when their matrix is known to undergo massive remodeling to repair and restore healthy pelvic tissues, after delivery $[34,35]$. Specifically, the expression of genes for several matrix proteins essential to elastic matrix assembly (e.g., fibrillin, elastin, fibulin and LOX) and their synthesis, are highly up regulated at this time [36]. 
Citation: Venkataraman L, Lenis AT, Couri BM, Damaser MS, Ramamurthi A (2012) Induced Regenerative Elastic Matrix Repair in LOXL1 Knockout Mouse Cell Cultures: Towards Potential Therapy for Pelvic Organ Prolapse. J Tissue Sci Eng 3:120. doi:10.4172/2157-7552.1000120

Page 6 of 8

This enhanced elastogenic response aids in the reorganization and reassembly of stable pelvic tissue post-partum.

The elastic matrix components of pelvic tissues are known to experience homeostatic disturbances and degradative changes in women with POP [37]. Whether these changes are a causative factor in pelvic floor relaxation and herniation, or are an outcome of the process, is incompletely understood [38]. Animal models of POP suggest that changes to the ECM of the vaginal tissue, occurring during normal pregnancy and parturition, are not restored to a normal, pre-pregnant state post-partum [39]. This implicates a pathologic deterioration of the vaginal tissue ECM that begins decades, before POP clinically manifests $[11,40,41]$.

Among structural ECM proteins, elastin, a major component of elastic fibers, provides resilience and mechanical stability to pelvic tissues [36,42]. Elastic fibers also critically maintain the healthy phenotype and function of SMCs, regulating vital cell signaling pathways. In this regard, it is likely that impaired elastic matrix repair and regeneration post-partum would limit return of the tissue to a pre-pregnancy state, and thus contribute to gradual POP development. Currently, there is no therapy that can prevent, impede or regress this process. The purpose of the present study is to investigate the possibility of an elastogenic therapy that could induce vaginal cells, to regenerate a healthy elastic matrix in pelvic tissues post-partum, towards slowing or even arresting POP development.

The present study utilized VSMCs harvested and isolated from a knock-out mouse lacking the gene expressing LOXL1, a well characterized animal model of POP [43]. LOXL1, a member of the LOX family, is a copper-dependent enzyme that oxidatively deaminates lysine residues on tropoelastin, mediating spontaneous crosslinking between monomers and forming the elastin polymer [44]. LOXL1 colocalizes with both the microfibrillar scaffolding protein fibulin-5 and elastin in the extracellular space [45]. Despite anatomical differences in pelvic floor orientation, POP in LOXL1 knockout mice is etiologically similar to human POP in that (a) prolapse development occurs mainly following parturition, (b) severity of POP increases with increasing parity, (c) cesarean delivery delays and reduces severity of prolapse, (d) heterogeneity of prolapse compartment contents can be observed on MRI, and (e) presence of dysfunctional urinary patterns potentially indicating stress urinary incontinence, a common co-morbid pelvic floor disorder $[3,11,43]$.

While clinical studies support a role for LOXL1 deficiency in POP pathogenesis, the evidence thus far is conflicting and inconsistent Nonetheless, reports suggest that the disorder is likely to be polygenetic in most women $[37,46]$. Despite some differences compared to the clinical condition, LOXL1 KO mice exhibit elastic matrix homeostatic disturbances and also develop POP, which provide investigators a pathophysiology-driven model to test novel therapies that address attenuating and restoring these pathological mechanisms.

Data from the present study shows that VSMCs from a LOXL1 $\mathrm{KO}$ mouse can synthesize the elastin precursor, tropoelastin, but deposit elastic matrix in the form of sparse, immature and interrupted fiber-like structures. This data also demonstrates that these cells can
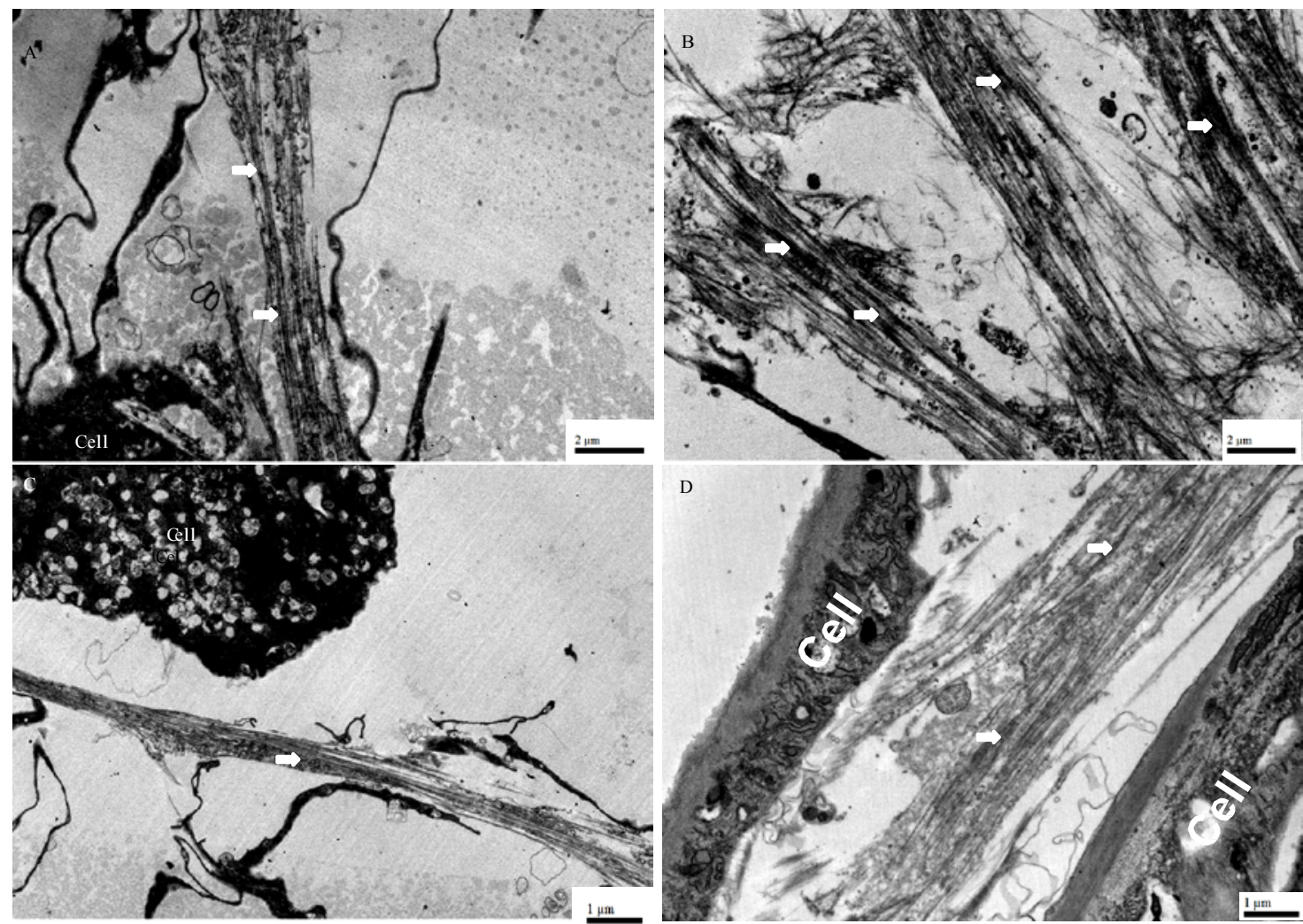

Figure 6: Example transmission electron microscopy images showing sporadic and aberrant elastin fibers (red arrows in A, C) in control cultures, while more abundant and mature fibers (red arrows in B, D) in EF-treated cultures. Magnification: $\mathbf{A}$ and $\mathbf{C}: 4400 \mathrm{x}(\mathrm{scale}$ bar $=2 \mu \mathrm{m}), \mathbf{B}$ and $\mathbf{D}: 11,500 \mathrm{x}(\mathrm{scale}$ bar $=1 \mu \mathrm{m})$. ECM $=$ extracellular matrix. 
be induced to significantly increase both elastin mRNA expressions (Figure 5), as well as deposit higher quantities of matrix elastin (Figure 4). RT-PCR confirmed that increase in elastin synthesis occurred following significant upregulation at the mRNA levels, and was independent of cell proliferation rates. Although, this increase in elastin gene expression was mirrored by increases in tropoelastin protein production, the difference between treated and untreated cultures was deemed statistically insignificant. These results contradict previous studies on aortic SMCs [27,29], wherein EFs stimulated significant increase in tropoelastin production. Despite this, the addition of EFs resulted in a $2.6 \pm 1.4$-fold increase in total matrix elastin compared to untreated VSMCs. This difference was observed primarily as the less-crosslinked alkali-soluble matrix elastin fraction, similar to that reported in previous studies on EF-treated aortic SMCs [27,45]. Since the quantities of tropoelastin synthesized by cells in both cases were insignificantly different, addition of EFs potentially contributes to matrix assembly processes, downstream from tropoelastin synthesis.

On the other hand, despite the addition of EFs, the lack of any increase in synthesis of the more crosslinked alkali-insoluble matrix-elastin fraction, could be indicative of the importance and indispensability of LOXL1-dependant cross-linking in the formation of mature elastin [47]. Previous studies have shown that the process of formation of mature matrix elastin involves a significant increase in LOX gene expression, and protein synthesis and activity [48]. Although, the tested dose combination of EFs was found to enhance LOX gene expression, this increase was deemed statistically insignificant. Nevertheless, it is certainly possible that any such increase in LOX mRNA might have triggered some increase in LOX protein synthesis (not measured), thereby compensating for absence of LOXL1. Especially, since elastogenic effects of EFs are highly dose-dependent $[27,29,45]$, further studies with EF dose-variations are required to investigate potential for improving LOX-mediated crosslinking and elastic matrix deposition. One limitation with the present study is that the cultures were analyzed at a single, extended time-point (21 days). It is also possible that compensatory mechanisms to overcome the lack of crosslinking enzymes in a LOXL1-deficient microenvironment may be more pronounced, at culture durations longer than 21 days. The formation and accumulation of elastic fibers may act as nucleation sites, for further tropoelastin deposition and fiber growth at a later time point.

Further, this study investigated results from VSMCs harvested from whole vagina of one multiparous prolapsed LOXL1 KO mouse. Effects of parity, time since previous delivery, age, and prolapse status may all affect the ability of VSMCs, to respond to EFs. Finally, the phenotypic implications of increased matrix elastin on LOXL1 KO VSMCs towards overcoming POP in vivo, are yet unknown and necessitate further studies, using the therapy in vivo.

Despite these limitations, EFs significantly improve overall architecture of elastic matrix. As observed by transmission electron micrographs of control cultures, interrupted/incomplete elastic fibers were distributed between VSMCs. In contrast, EF-treated cultures showed significantly more elastic matrix, which appeared in organized bundles of fibers between cells, with fiber diameters corresponding to that typical for mature elastic fibers $(300 \mathrm{~nm}-2 \mu \mathrm{m})[1,42]$. Improved elastic fiber assembly may be a likely outcome of organized deposition of fibrillin scaffolds, followed by enhanced tropoelastin recruitment and crosslinking [49]. In addition to new fiber formation, attenuated expression and/or activity of matrix degrading enzymes can greatly help preserve and maintain matrix integrity [50]. Newly formed matrix structures, further serve as nucleation sites for fiber growth and crosslinking [49]. Supporting this, MMPs, specifically elastolytic MMPs -2 and -9 , have been shown to be involved in POP development and/or propagation [5,51,52]. There is also evidence that in animal models of POP such as fibulin $-5 \mathrm{KO}$ mice and LOXL1 KO mice, enzyme activities of MMPs -2 and -9 are highly upregulated $[5,53,54]$. This may account for the presence of interrupted and aberrant elastic fibers in LOXL1 KO mouse VSMCs. In this light, it is quite possible that the EF-induced improvement in overall elastic matrix fiber formation and intactness, are at least in part due to the inhibitory effects of EFs on MMPs [27,29]. Further studies designed to investigate the role of MMPs in the LOXL1 $\mathrm{KO}$ mouse, and the regulatory potential of EFs, are warranted.

\section{Conclusion}

This study provides evidence that SMCs from prolapsed vaginas of LOXL1 KO mice are responsive to elastogenic stimulation and improves elastin synthesis, matrix deposition and fiber formation. Developing a pathophysiology-driven preventative-therapy for POP development and progression, and for limiting complications from surger, as well as its recurrence, will significantly improve the quality of life of women suffering from this condition, and at the same time reduce the massive economic burden. The promising results from this study merits further studies to develop therapeutics based on elastogenic induction of cells to overcome development and progression of POP.

\section{Acknowledgements}

This work supported in part by the Cleveland Clinic (Ramamurthi A) and the Rehabilitation Research and Development Service of the Department of Veterans Affairs (Damaser M).

\section{References}

1. Pasquali-Ronchetti I, Baccarani-Contri M (1997) Elastic fiber during development and aging. Microsc Res Tech 38: 428-435.

2. Antonicelli F, Bellon G, Debelle L, Hornebeck W (2007) Elastin-elastases and inflamm-aging. Curr Top Dev Biol 79: 99-155.

3. Liu X, Zhao Y, Pawlyk B, Damaser M, Li T (2006) Failure of elastic fibe homeostasis leads to pelvic floor disorders. Am J Pathol 168: 519-528.

4. Zong W, Stein SE, Starcher B, Meyn LA, Moalli PA (2010) Alteration of vaginal elastin metabolism in women with pelvic organ prolapse. Obstet Gynecol 115 953-961.

5. Rahn DD, Acevedo JF, Word RA (2008) Effect of vaginal distention on elastic fiber synthesis and matrix degradation in the vaginal wall: potential role in the pathogenesis of pelvic organ prolapse. Am J Physiol Regul Integr Comp Physiol 295: R1351-R1358.

6. Moon YJ, Choi JR, Jeon MJ, Kim SK, Bai SW (2011) Alteration of elastin metabolism in women with pelvic organ prolapse. J Urol 185: 1786-1792.

7. Smith FJ, Holman CD, Moorin RE, Tsokos N (2010) Lifetime risk of undergoing surgery for pelvic organ prolapse. Obstet Gynecol 116: 1096-1100.

8. Dällenbach P, Jungo Nancoz C, Eperon I, Dubuisson JB, Boulvain M (2012) Incidence and risk factors for reoperation of surgically treated pelvic organ prolapse. Int Urogynecol J 23: 35-41.

9. Diwadkar GB, Barber MD, Feiner B, Maher C, Jelovsek JE (2009) Complication and reoperation rates after apical vaginal prolapse surgical repair: a systematic review. Obstet Gynecol 113: 367-373.

10. Salvatore S, Athanasiou S, Digesu GA, Soligo M, Sotiropoulou M, et al. (2009) Identification of risk factors for genital prolapse recurrence. Neurourol Urodyn 28: 301-304.

11. Jelovsek JE, Maher C, Barber MD (2007) Pelvic organ prolapse. Lancet 369 1027-1038.

12. Visco AG, Yuan L (2003) Differential gene expression in pubococcygeus muscle from patients with pelvic organ prolapse. Am J Obstet Gynecol 189 102-112. 
Citation: Venkataraman L, Lenis AT, Couri BM, Damaser MS, Ramamurthi A (2012) Induced Regenerative Elastic Matrix Repair in LOXL1 Knockout Mouse Cell Cultures: Towards Potential Therapy for Pelvic Organ Prolapse. J Tissue Sci Eng 3:120. doi:10.4172/2157-7552.1000120

Page 8 of 8

13. Mushkat $Y$, Bukovsky I, Langer $R$ (1996) Female urinary stress incontinence-does it have familial prevalence? Am J Obstet Gynecol 174: 617-619.

14. Leppert PC (1995) Anatomy and physiology of cervical ripening. Clin Obstet Gynecol 38: 267-279.

15. Starcher B, Percival S (1985) Elastin turnover in the rat uterus. Connect Tissue Res 13: 207-215

16. Yamamoto K, Yamamoto M, Akazawa K, Tajima S, Wakimoto H, et al. (1997) Decrease in elastin gene expression and protein synthesis in fibroblasts derived from cardinal ligaments of patients with prolapsus uteri. Cell Biol In 21: $605-611$

17. Ewies AA, Al-Azzawi F, Thompson J (2003) Changes in extracellular matrix proteins in the cardinal ligaments of post-menopausal women with or without prolapse: a computerized immunohistomorphometric analysis. Hum Reprod 18: $2189-2195$

18. Kökçü A, Yanik F, Cetinkaya M, Alper T, Kandemir B, et al. (2002) Histopathological evaluation of the connective tissue of the vaginal fascia and the uterine ligaments in women with and without pelvic relaxation. Arch Gynecol Obstet 266: 75-78.

19. Chen B, Wen Y, Polan ML (2004) Elastolytic activity in women with stress urinary incontinence and pelvic organ prolapse. Neurourol Urodyn 23: 119-126.

20. Chen B, Wen Y, Zhang Z, Guo Y, Warrington JA, et al. (2006) Microarray analysis of differentially expressed genes in vaginal tissues from women with stress urinary incontinence compared with asymptomatic women. Hum Reprod 21: $22-29$

21. Barber MD (2011) Incontinence: should mesh be used to correct anterior vaginal prolapse? Nat Rev Urol 8: 476-478.

22. Joddar B, Ramamurthi A (2006) Fragment size- and dose-specific effects of hyaluronan on matrix synthesis by vascular smooth muscle cells. Biomaterials 27: 2994-3004

23. Joddar B, Ramamurthi A (2006) Elastogenic effects of exogenous hyaluronan oligosaccharides on vascular smooth muscle cells. Biomaterials 27: 56985707.

24. Dai J, Losy F, Guinault AM, Pages C, Anegon I, et al. (2005) Overexpression of transforming growth factor-beta1 stabilizes already-formed aortic aneurysms: a first approach to induction of functional healing by endovascular gene therapy. Circulation 112: 1008-1015.

25. Losy F, Dai J, Pages C, Ginat M, Muscatelli-Groux B, et al. (2003) Paracrine secretion of transforming growth factor-beta1 in aneurysm healing and stabilization with endovascular smooth muscle cell therapy. J Vasc Surg 37 1301-1309.

26. Shanley CJ, Gharaee-Kermani M, Sarkar R, Welling TH, Kriegel A, et al. (1997) Transforming growth factor-beta 1 increases lysyl oxidase enzyme activity and mRNA in rat aortic smooth muscle cells. J Vasc Surg 25: 446-452.

27. Kothapalli CR, Taylor PM, Smolenski RT, Yacoub MH, Ramamurthi A (2009) Transforming growth factor beta 1 and hyaluronan oligomers synergistically enhance elastin matrix regeneration by vascular smooth muscle cells. Tissue Eng Part A 15: 501-511.

28. Gacchina CE, Deb P, Barth JL, Ramamurthi A (2011) Elastogenic inductability of smooth muscle cells from a rat model of late stage abdominal aortic aneurysms. Tissue Eng Part A 17: 1699-1711.

29. Kothapalli CR, Gacchina CE, Ramamurthi A (2009) Utility of hyaluronan oligomers and transforming growth factor-beta1 factors for elastic matrix regeneration by aneurysmal rat aortic smooth muscle cells. Tissue Eng Part A 15: $3247-3260$

30. Labarca C, Paigen K (1980) A simple, rapid, and sensitive DNA assay procedure. Anal Biochem 102: 344-352.

31. Bouzeghrane F, Reinhardt DP, Reudelhuber TL, Thibault G (2005) Enhanced expression of fibrillin-1, a constituent of the myocardial extracellular matrix in fibrosis. Am J Physiol Heart Circ Physiol 289: H982-H991.

32. Livak KJ, Schmittgen TD (2001) Analysis of relative gene expression data using real-time quantitative PCR and the 2(-Delta Delta C(T)) Method. Methods 25: 402-408
33. Tremollieres F (2010) [Connective tissue and prolapse genesis]. Gynecol Obstet Fertil 38: 388-393.

34. Timmons B, Akins M, Mahendroo M (2010) Cervical remodeling during pregnancy and parturition. Trends Endocrinol Metab 21: 353-361.

35. Rahn DD, Ruff MD, Brown SA, Tibbals HF, Word RA (2008) Biomechanical properties of the vaginal wall: effect of pregnancy, elastic fiber deficiency, and pelvic organ prolapse. Am J Obstet Gynecol 198: 590.e1-e6.

36. Consonni SR, Werneck CC, Sobreira DR, Kühne F, Moraes SG, et al. (2012) Elastic fiber assembly in the adult mouse pubic symphysis during pregnancy and postpartum. Biol Reprod 86: 151, 1-10.

37. Chen B, Yeh J (2011) Alterations in connective tissue metabolism in stress incontinence and prolapse. J Urol 186: 1768-1772.

38. Man WC, Ho JY, Wen Y, Sokol ER, Polan ML, et al. (2009) Is lysyl oxidaselike protein-1, alpha-1 antitrypsin, and neutrophil elastase site specific in pelvic organ prolapse? Int Urogynecol J Pelvic Floor Dysfunct 20: 1423-1429.

39. Abramowitch SD, Feola A, Jallah Z, Moalli PA (2009) Tissue mechanics, animal models, and pelvic organ prolapse: a review. Eur J Obstet Gynecol Reprod Biol 144: S146-S158.

40. Lowder JL, Debes KM, Moon DK, Howden N, Abramowitch SD, et al. (2007) Biomechanical adaptations of the rat vagina and supportive tissues in pregnancy to accommodate delivery. Obstet Gynecol 109: 136-143.

41. Alperin M, Feola A, Duerr R, Moalli P, Abramowitch S (2010) Pregnancy- and delivery-induced biomechanical changes in rat vagina persist postpartum. Int Urogynecol J 21: 1169-1174

42. Leppert PC, Yu SY (1991) Three-dimensional structures of uterine elastic fibers: scanning electron microscopic studies. Connect Tissue Res 27: 15-31.

43. Lee UJ, Gustilo-Ashby AM, Daneshgari F, Kuang M, Vurbic D, et al. (2008) Lower urogenital tract anatomical and functional phenotype in lysyl oxidase like-1 knockout mice resembles female pelvic floor dysfunction in humans. Am J Physiol Renal Physiol 295: F545-F555.

44. Csiszar K (2001) Lysyl oxidases: a novel multifunctional amine oxidase family Prog Nucleic Acid Res Mol Biol 70: 1-32.

45. Venkataraman L, Ramamurthi A (2011) Induced elastic matrix deposition within three-dimensional collagen scaffolds. Tissue Eng Part A 17: 2879-2889.

46. Klutke J, Ji Q, Campeau J, Starcher B, Felix JC, et al. (2008) Decreased endopelvic fascia elastin content in uterine prolapse. Acta Obstet Gyneco Scand 87: 111-115.

47. Liu X, Zhao Y, Gao J, Pawlyk B, Starcher B, et al. (2004) Elastic fiber homeostasis requires lysyl oxidase-like 1 protein. Nat Genet 36: 178-182.

48. Fornieri C, Baccarani-Contri M, Quaglino D Jr, Pasquali-Ronchetti I (1987) Lysyl oxidase activity and elastin/glycosaminoglycan interactions in growing chick and rat aortas. J Cell Biol 105: 1463-1469.

49. Wagenseil JE, Mecham RP (2007) New insights into elastic fiber assembly. Birth Defects Res C Embryo Today 81: 229-240.

50. Mecham RP, Broekelmann TJ, Fliszar CJ, Shapiro SD, Welgus HG, et al. (1997) Elastin degradation by matrix metalloproteinases. Cleavage site specificity and mechanisms of elastolysis. J Biol Chem 272: 18071-18076.

51. Budatha M, Roshanravan S, Zheng Q, Weislander C, Chapman SL, et al. (2011) Extracellular matrix proteases contribute to progression of pelvic organ prolapse in mice and humans. J Clin Invest 121: 2048-2059.

52. Chen BH, Wen Y, Li H, Polan ML (2002) Collagen metabolism and turnover in women with stress urinary incontinence and pelvic prolapse. Int Urogynecol Pelvic Floor Dysfunct 13: 80-87.

53. Wieslander CK, Rahn DD, Mclntire DD, Acevedo JF, Drewes PG, et al. (2009) Quantification of pelvic organ prolapse in mice: vaginal protease activity precedes increased MOPQ scores in fibulin 5 knockout mice. Biol Reprod 80 : 407-414.

54. Drewes PG, Yanagisawa H, Starcher B, Hornstra I, Csiszar K, et al. (2007) Pelvic organ prolapse in fibulin-5 knockout mice: pregnancy-induced changes in elastic fiber homeostasis in mouse vagina. Am J Pathol 170: 578-589. 